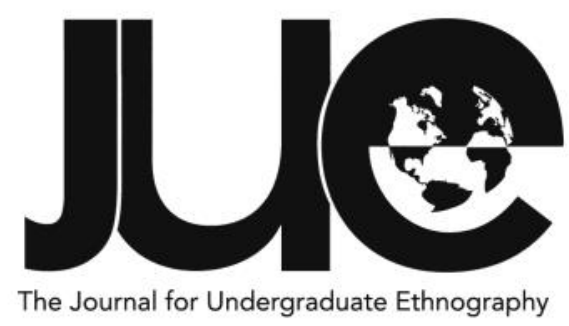

\title{
When Your Neighbourhood Changes: Living Through Gentrification in Amsterdam Oud-West
}

\section{Sophia Rettberg \& Janna Willems}

\author{
University College Maastricht, \\ s.rettberg@student.maastrichtuniversity.nl \\ jb.willems@student.maastrichtuniversity.nl
}

\section{ABSTRACT}

This qualitative study investigates the lived experiences of gentrification for locals in the urban neighbourhood of Oud-West in Amsterdam. A gentrification policy was used to turn this neighbourhood with a relatively low socioeconomic status and limited property investment into an attractive area of reinvestment and economic activity. For locals, this strategy resulted in changes to the urban landscape, such as soaring housing prices, new investment projects, tourism, and a new, transient, young urban professional group of inhabitants. Following this demographic change, the locals that have not been physically displaced nevertheless experience a sense of displacement. By analyzing the concept of 'transience', this study shows how the relatively short and less integrated stay of global young urban professionals results in a perceived loss of social cohesion. Moreover, this young urban professional population's increasing demand for an 'Airspace' type of hospitality radically changes local and authentic businesses, resulting in a perceived lack of diversity and authenticity. Furthermore, locals report how they experience new inhabitants to be less tolerant towards 'big city life', and have a stronger sense of malleability.

Keywords: gentrification, Amsterdam, airspace, locals, neighbourhood change, transience 
G entrification is the process of a more affluent population moving into an area of lower socioeconomic status, typically accompanied by changing street views, rising prices, and the displacement of locals. Gentrification has been accelerating in cities worldwide. Often established by projects intentionally designed to reshape rundown areas, a gentrifying neighbourhood is marked by the rapid growth of new enterprises, hospitality businesses (such as new cafés, bars and restaurants), and property investment. Following this trend, Amsterdam's neighbourhood of Oud-West, traditionally a less affluent and multicultural area, has been gentrifying, with soaring housing prices since 2005 (City of Amsterdam 2016), and notable changes in its street view since 2010 (Agora Europa 2015; Borrel 2017). Bordering the inner city of Amsterdam, the neighbourhood has increasingly become frequented by tourists and inhabited by a more affluent population. In line with existing literature, the evaluation of gentrification is complex: on the one hand, it is regarded as a welcome advancement of the city's economy and competitiveness, livability and real estate value. On the other hand, different effects on the population include living through forced displacement, loss of affordable housing, community resentment and loss of social diversity (Atkinson 2004). Rather than understanding gentrification as a commercial development, this research aims to approach the discussion of gentrification in a critical manner by articulating its effects on long-time residents (defined as people who were either born in Oud-West or have lived there for at least 25 years) and their neighbourhood.

This article seeks to answer the question: How do locals of Amsterdam Oud-West experience living in an area that has been gentrifying rapidly? In order to answer this question, and using the relevant existing literature as a starting point, this study approaches gentrification in a multidimensional manner. Our main findings are that Oud-West has changed from a residential neighbourhood to a neighbourhood popular among an international, young urban professional, transient population. Whereas some of the local population has been displaced, most people face a similar sense of displacement without actually being physically removed.

While research on gentrification often focuses on its effects on a neighborhood's existing population, this article is concerned with the perceived 'transience' of new people in the neighbourhood of Oud-West by locals, as well as the concept of 'Airspace' (introduced later). This research is of a qualitative nature, and aims to examine gentrification through the lens of local residents. The study is conducted by two researchers, one local to Oud-West and one who is originally from Cologne, Germany, and has lived in the Netherlands for two years.

In the second section of this paper, the theoretical framework will be outlined by means of a literature review. The third section provides relevant background information on Oud-West. The fourth section discusses the methodology as well as the study's strengths and limitations. We then describe our findings on how existing residents experience this form of gentrification: first, they see that the housing market will make it difficult for them and their children to remain in the neighborhood; second, they react to a change in demographics and declining diversity; third, they feel a lack of social cohesion with regards to new inhabitants ('the gentrifiers'); fourth, to them, new inhabitants are less tolerant, which is changing the neighbourhood; and finally, they feel estranged through the changing nature, and increasing homogenisation of shops and services.

In order to discuss the effects of gentrification more concretely in our interviews, we include the two case studies of De Hallen and De Rond. Both cases resemble two key reference points that symbolize the neighbourhood's recent development and illustrate how existing residents have been reacting to the gentrifying process. 


\section{Gentrification and the Creation of "Airspace"}

Gentrification, "the creation of space for the affluent" (Doucet et al. 2011, 1438), is used by policy makers to develop neighbourhoods with relative poverty and limited property investment into attractive areas of reinvestment and commodification. Yet in reality, these practices entail crucial changes for local residents. Previous qualitative research on the lived experience of locals in gentrifying areas shows that its evaluation is complex. Doucet's (2011) research in Rotterdam mainly discusses the influx of new shops, renovated housing and the upgraded image of a neighbourhood, including falling crime rates, and demonstrates that locals recognise the positive aspects of an improved neighbourhood. Reportedly, locals feel proud to live in a now popular neighbourhood that was once an undesirable one (ibid). Unlike other research, Doucet reports that no tension was perceived between new places catering to new residents and existing places for locals.

The city's aim in developing a run-down area and attracting different income groups is to improve the neighbourhood and create a community that mirrors the socioeconomic, cultural and ethnic diversity of the city's diverse population at large (Atkinson 2004; Doucet 2011). The outcome, however, is typically a takeover by the more affluent layer of gentrifiers in terms of housing, shops, and hospitality, rather than cohesion. Gentrification has therefore been described as an attempt to conceal rather than solve inequalities of income and opportunity. In the long run, as the original inhabitants are directly or indirectly forced to relocate, the intended diversity within the population fades as the neighbourhood homogenises into an upper-class area (Atkinson 2004; Slater 2006; Lees 2008; Boterman \& Gent 2014). Further research by Criekingen (2009) and Shaw \& Hagemans (2015) reveals a discrepancy between locals and new residents in terms of integration and sense of community. On the one hand, new tenants are usually young adults with a higher education degree, who themselves associate gentrification with the positive notion of upward social mobility. On the other hand, locals indicate that newcomers do not invest time and effort into the community, and do not integrate into the culture of sociability, which is often based in and around local shops (Butler 2003). Consequently, a more affluent neighbourhood comes with an uneven distribution of wealth, which changes shop fronts and their pricing. This has negative consequences for the lowerincome classes and their social life. In Shaw and Hagemans' (2015) study, participants describe a lack of choice of affordable stores, such as butchers and fruit shops, because local places start targeting the new, more affluent, consumer. In the process of gentrification, old shops close and are replaced by new ones, isolating gentrifiers from the existing community (Lees 2008; Gent 2013). Locals feel increasingly segregated from new stores and restaurants, which is not deliberate but the result of income disparity and lifestyle differences (Butler 2003).

As explained by Shaw and Hagemans (2015), displacement does not require physical removal, but also refers to relational and social elements. They argue that the dream of 'revitalisation without displacement', the evidence-based policy dream of gentrification without negative impacts, is very problematic. Gentrification is not only problematic in terms of displacement, but a sense of loss of place through a transforming neighbourhood. The gentrification process requires many local shops that serve as local meeting points to close down, which strongly impacts the neighbourhood's lower income groups, hence creating a sense of loss of place through a transforming neighbourhood. Gentrification is not only problematic in terms of displacement, but over time, communities become alienated from their neighbourhood, and locals start to leave (Butler 2003). This is in accordance with Butler (2003), who argues that despite the emerging social disparities, local populations of gentrifying neighbourhoods still feel a strong emotional attachment to the area. However, their perceived identification with the neighbourhood declines, which points to the dynamics of displacement. Gentrification is not only problematic in terms of displacement, but over time communities become alienated from their neighbourhood and locals start to leave (ibid). 
The existing local cafés and shops that close down are replaced by certain types of places that cater to the new, transient, population. By transient, we mean the fleeting, on-the-go characteristic of the international young urban professionals that live in Amsterdam Oud-West temporarily, ranging from a week to a couple of years. The phenomenon of global transience is described in Chayka's (2016) article 'Airspace', which elaborates on the above-mentioned culture of 'the gentrifiers' and its effects on local culture. The typical gentrifier is described as privileged, young, and affluent, someone who moves to cities like Amsterdam for work, often for a limited amount of time. Since the introduction of online accommodation services like Airbnb, the international young urban professional has started to live a different lifestyle. The connectivity of social media facilitates the search for authentic experience, staying at local people's homes and going to a local café rather than conventional hotels and tourist traps. He therefore coins the concept of Airspace, which describes the phenomenon of new cafes, bars and restaurants favoured by a global transient population as described above. As Chayka explains, gentrifiers are a symptom of globalisation and a new form of modern cultural imperialism. He states that while a gentrifying neighbourhood becomes "less diverse as buildings are renovated and storefronts replaced", urban areas around the world start resembling each other and become interchangeable. As local shops and hospitality start to cater for their new clientele to meet the demand of their 'authentic' needs, they turn into Airspace. This is defined as "the realm of coffee shops, bars, start-up offices, [...] that share the same hallmarks everywhere you go: [...] Minimalist furniture. Craft beer and avocado toast. Reclaimed wood. Industrial lighting. Cortados. Fast internet."

With regards to gentrification and the demand for something unique, exotic and noncorporate, the designated tourist space in the city centre shifts to residential areas. Therefore, Airspace refers to a globalised common culture and identity for the gentrifier, which often comes at the cost of truly authentic places, creating a division between those who can afford the inner urban area claimed by airspace, and those who cannot (Chayka 2016; Sloane 2016).

\section{Introducing Oud-West and its Demographic Changes}

Oud-West is one of the most densely populated neighbourhoods of Amsterdam, with 13,000 homes per square kilometer (Gemeente Amsterdam 2017a). The entire area was built between 1875 and 1940 on what were then the fringes of the city. As explained by Schade (1981), cheap and substandard dwellings were created to accommodate the working and lower middle classes during a rapid expansion of Amsterdam during the industrial revolution. The houses were of such bad quality that they often collapsed; new building regulations slightly improved the situation throughout the beginning of the 20th century, but the neighbourhood was still dominated by cheap rental houses. Oud-West remained a typical lower and lower middle class neighbourhood for the remainder of the 20th century.

Over the past 20 years, the area has undergone major changes, which the 2017 area report of the municipality of Amsterdam provides insights into (Gemeente Amsterdam 2017a). First, it explicitly mentions the presumably positive effects of gentrification. Social housing is sold off to the private sector, the creative industry and tourism are the fastest growing industries, unemployment and criminality rates drop, and children have better average school results. $48 \%$ of the inhabitants of Oud-West are "New Urbanites", a statistical category for people that have moved to Amsterdam from other parts of the Netherlands and 'the Western World' when they were between 18 and 55 years old. The report states that "Oud-West (...) has gone through major developments over the past 20 years. The area was coping with major deprivations, both in terms of the maintenance of buildings and in a socioeconomic sense. (...) Multiple rental properties, both owned by corporations and private owners, were sold off, making the area accessible to other groups of people" (Gemeente Amsterdam 2017a, p. 2).

Whereas the previously mentioned report provides statistical evidence of socioeconomic changes, understanding the decreasing ethnic and racial diversity is more challenging. OudWest is home to a diverse group of residents, however, there are simply no statistics available 
on ethnicity, because it is not commonly used as a category of analysis in the Netherlands. The only existing data of use refer to nationality and migration background. In terms of nationality, there were 177 nationalities living in Oud-West in 2007, and that number had dropped to a varying range of 80 to 109 in 2014, depending on the area of Oud-West (Gemeente Amsterdam 2014). Migration background is more complicated, as the definitions have changed over the years, with categories such as "industrialised/non-industrialised" and "western/non-western" all meaning something slightly different. Moreover, inhabitants are only seen as having a migration background if they are first or second generation migrants; effectively, the grand-children of migrants that arrived in the Netherlands in the 1950s and 1960s are not categorised as migrants, but simply as Dutch. 2017 statistics do show a decline in inhabitants with a Surinamese, Antillean, Turkish, Moroccan and "non-Western" or "non-industrialised" migration background when compared to 2002 (Het Amsterdamse Bureau voor Onderzoek en Statistiek, 2002; Gemeente Amsterdam 2017b).

These demographic changes were accompanied by transformations in the street view, shop fronts and hospitality. Over the past decade, almost all main streets in Oud-West have undergone dramatic changes (Borrel 2017). Two illustrative examples of these changes that are discussed by participants in this study are the opening of the De Hallen and the closing of the De Rond bakery. The two case studies of De Hallen and De Rond are two of the most illustrative examples of gentrification in Oud-West. The renovation and refurbishment of former tram station the De Hallen is the most prominent case of this process, and therefore serves as a focal point of the study. The municipality of Oud-West had been struggling to find a purpose for the De Hallen, which was in use as a tram depot until 1996, and was increasingly pressured to take action when the building was squatted in 2010 (Agora Europa 2015; Borrel 2017). Finally, a solution was found with a group of investors, and a range of different concept stores and a cinema were opened in the newly renovated complex in 2014. The renovation process was controversial, and can be seen as symbolic of overall change in the neighbourhood.
De Rond, located at the heart of Oud-West, was one of the very few bakeries in Amsterdam with a permit to open its doors as early as 3am. It was an institution for those looking for afterhours food for over 40 years. The bakery's new neighbours, having bought an apartment in the adjoining pand [a unit of four or five floors of apartments stacked on top of each other, usually owned by a private landlord or cooperation, typically part of a larger housing block], started filing complaints regarding noise, smell and vermin (AT5 2016; Posthumus 2016). After a lengthy process and local protests, the bakery had to close its doors in January 2017.

\section{Methodology}

This qualitative research took place from September 2016 until January 2017 and aims at assessing the lived experiences of gentrification for locals. Thirteen semi-structured in-depth interviews with a total of 17 participants were conducted, lasting roughly 60 minutes each. Eight interviews were conducted with individuals to obtain their perceptions and experiences. Three interviews were conducted with two generations, one mother and daughter interview and two father and daughter interviews, which provided further insight into the dynamics of gentrification as experienced by different generations. Furthermore, an interview was held with a father and son who have owned a local business in Oud-West since 1989, but who live elsewhere in Amsterdam. The design of our interview guide was mainly shaped by previous literature on gentrification, and topics that emerged during the interview with the neighbourhood coordinator of OudWest held prior to all other interviews. The neighbourhood coordinator liaises between inhabitants and the City council, and accommodates citizens' initiatives such as street parties and urban gardens. We therefore interviewed him to gain insights into the municipality's perspective on the effects of gentrification of Oud-West. We refrained from using the word 'gentrification' due to its negative connotation (Atkinson 2004). The two case studies of De Hallen and De Rond are suitable topics of discussion, providing allegories for wider issues. All interviews were conducted either in Dutch (7) or English (6) and took place at participants' homes or workplaces. One interview was conducted via 
Skype. We selected participants who were either born in Oud-West or who have lived there for at least 25 years. Twelve respondents were from a Dutch background, one from a Dutch-North African background, two with North African background and two with a Southern European background.

The context of the study was partially personal, as one of the researchers is local to Oud-West. Therefore, our sample was recruited through personal communication and snowballing. The personal factor enabled the disclosure of intimate information based on confidentiality and trust. The second researcher is not from the Netherlands. She took the role of the outsider, which allowed for clarifications that invited participants to give detailed descriptions of topics that came up during the interviews. It can be argued that this is one of the strengths and weaknesses of the study. Both researchers were present in all interviews, which were recorded and transcribed in their original language. All transcripts were skimmed to identify big themes and collect first impressions, followed by an in-depth analytic process in order to create coding themes, words and phrases. Coding was partially based on the literature review and partially open to ensure that new data could be captured. The relevant parts of the Dutch interviews were translated into English for the means of this report. Every participant was given a pseudonym in order to guarantee confidentiality (see appendix I).

During the interviews, it became clear that all participants were to some extent aware of the current public debate around gentrification. Some interviewees explicitly understood our research to be of a political nature or were wellinformed on theories of gentrification, and clearly approached our questions with a certain agenda in mind, exaggerating either the positive or the negative aspects of gentrification. Therefore, we must take into account that our participants' previous attitudes on the debate of gentrification could potentially have influenced the information they shared with us. Both the roles of the researcher as an outsider and insider could have encouraged participants to respond to more socially desirable accounts, or inhibited them from sharing their true opinion or experiences of gentrification; our intentions and integrity as researchers were questioned on a number of occasions. However, opinions were diverse, and cover the full stretch from overly positive to overly negative. We believe their explicitness has enabled us to identify exaggerations.

The majority of the interviewees reflected on the widespread critique that gentrification has received in the media, and in turn compensated by emphasising the positive changes during the earlier open questions. In line with previous research, essential renovations, increased safety and overall tidiness were highlighted. The best insights on the lived experience of our interviewees occurred during the personal questions regarding their past and future in Oud-West, what they find important in their neighbourhood, and their ability to identify with the neighbourhood. It was particularly during personal stories and anecdotes that reflected on the housing market, new neighbours, new shops and cafés and changing street views that our interviewees gave us valuable information. Some interviewees indicated that they found it conflicting or hypocritical to embrace both the enjoyable and problematic sides of gentrification, and felt the need to pick a side in the beginning: luckily, most interviewees opened up about the complexities as we discussed more tangible examples later on.

Notably, most interviewees started the interview from a less critical position than the one they ended with, which reflects the complexity surrounding the discussion of neighbourhood change, or recent changes and their assessment as either positive or negative effects for local residents. In future research more attention should be paid to specific examples relating to gentrification, which in our study proved to enable participants to evaluate change in a more multifaceted manner. The critical approach toward gentrification on the negative as well as positive aspects enabled a profound assessment of the complexities during and after gentrifying processes. Moreover, the real implications of gentrification could have been extended to interviewing locals who were incentivised through monetary means to move to establish factors that could prevent involuntary displacement based solely 
on financial necessity. This would enable more inclusive socio-economic and ethnically diverse communities to occupy and claim their right to the city centre.

\section{The Housing Market: A Generational Property Problem}

Decreasing affordability of housing in Oud-West is a recurring theme in our interviews. Whereas living in Oud-West was accessible to a wide variety of people up until five years ago, two modal-income jobs combined are now not enough to rent or buy property. As social housing disappears (that is, apartments that are part of Amsterdam's affordable rental housing program), rental apartments have become scarce and solely available on the expensive private market. Panden (apartment building or properties) that become available on the housing market are exclusively bought by private investors or more affluent buyers. To illustrate the contrast, Morits explains that in the 1970s, two adjoining panden were sold "for 80.000 or 70.000 guilders" [roughly 35.000 euros]. On the contrary, in 2014 the run-down single pand where Tristan used to live in, which "[was] in quite a bad state and in need of renovations, especially the roof because it was almost collapsing", was sold to a group of investors for 1.55 million euros. There has been an increase in property sales, largely because of investors who buy dilapidated buildings or apartments, renovate them and sell them for profit. In fact, all tenants and homeowners report to receive up to fifty attempts of uitkopen a year, the process in which investors offer a sum of money to the tenant or homeowner to leave their homes to make space for project development. In a bought pand, apartments are often sold individually or rented out for higher prices. The purchasing price ranges between 450.000 euros to "1.1 million for one floor" (Alexandris). The increased popularity of Oud-West is illustrated by the rent paid by old and new residents. Fatima and Jaida have lived in Oud-West for the past 29 years and are paying 600 euros a month. New residents are expected to pay between 1400 (Fatima) and 2500 euros (Alexandris).

Housing prices affect locals hugely, especially regarding their future in Oud-West. The interviews reveal a notable difference between property owners and tenants. Those who own property can provide a future for their children in the neighbourhood, and have seen an extreme increase in the worth of their property. In comparison, tenants are certain that their children will end up living elsewhere, and they themselves cannot move into a different house if they wish to remain in Oud-West as the affordable housing has almost completely disappeared. Interestingly, almost all homeowners note that when they bought the house, they did so rather reluctantly. As Hendrik explains, "[in 1992] we had been waiting for four years. A good place to rent was impossible to find, with two bedrooms and a little more space... But yeah, we wanted to stay in the area. I'm a carpenter, so I'm quite handy, and we saw this pandje. It was really in a terrible state, but it was cheap, so we could afford it. I thought it would be too much work, but my wife was like, "We have to do it!" and yeah, in hindsight... It was a good choice." Hendrik's account underlines how Oud-West has changed from an underinvested and affordable neighbourhood.

Hendrik's daughter Stephanie moved into the second floor of the pand when it became available, illustrating a wider trend: all of the younger generation interviewees are only able to access the housing market in Oud West due to a parent-owned pand, as a tenant or as a (part) owner. Ella is in the process of buying an apartment in her mother's pand and notes:

For me it was easy, because I bought the apartment from my mother so it was not on the market... But more generally, the prices are extremely high and there is a lot of overbidding. (...) It is not possible to fund it at two full-time wages. (...) I've seen a lot of struggles from my friend group, many in my friend group still work it out, but hardly no-one works it out without the support of their parents... None of them succeeded in Oud-West [but in other areas of Amsterdam].

Such support is not available to all our interviewees: people like Tristan and Willem whose parents do not own property in the neighbourhood moved to adjoining 
neighbourhoods such as Nieuw West where houses are a little more affordable. Fatima is in her mid-20s and still lives in her family's rental apartment in Oud-West. As a supermarket cashier, she cannot afford to buy or rent anywhere nearby, including the adjoining neighbourhoods. Fabian lives in social housing, and explains that whenever social housing becomes available in his street, it is renovated and sold off on the real estate market, or upgraded to a rental house on the free market. As social housing has a typical architecture, many locals are surprised by this, as Tristan notes: “I thought to myself, 'Like, you can't just sell them because it just says social housing who will buy this?' and then they sold one ground floor for 3,000,000 euros last year and people have been mad about it. And I fully agree, because you need to save that [social housing opportunity]." Consequentially, these sell-offs mean the exclusion of social groups based on socioeconomic discrimination, forcing certain groups out of the neighbourhood who previously could afford to live there, and thereby increasingly making way for more affluent groups to move into Oud-West. All interviewees report similar dynamics in their streets, confirming the existing theories on rising prices and class segregation in gentrifying areas.

\section{Changing Demographics: Declining Diversity}

As we have seen in the previous section, the neighbourhood has seen a changing housing market, which brings with it an influx of people of a higher socioeconomic status. The image drawn by our interviewees is that Oud-West has changed from a multicultural working and lower middle class area to an area for international young urban professionals and tourists. Alexandris and Dimitri note: "You do notice more people with money and more expensive apartments and things like that... People tend to buy more new bikes or are willing to spend more on bike repairs."

Existing residents feel that the multicultural character of Oud-West is declining rapidly. Stephanie illustrates the decreasing diversity reported by most of our interviewees when talking about her school: "[in the mid-1990s] at my primary school - we were a group of 8 that were called the Hollanders, as a joke you know. But apart from that they were from Ghana, Turkey, and Morocco... Very diverse. And everyone was mingling happily, it was great fun. You should have a look at Kinkerhoek, where I went to school - when I look at my neighbours now, there will mainly be Dutch children with blonde hair and blue eyes. The area has definitely gotten less diverse." In further reflection on ethnic diversity, Hendrik talks about the community of different HinduPakistani families in the street, who all left for a neighbourhood in Nieuw-West in a relatively short amount of time. Their houses were old and run-down and they were likely financially incentivised to leave, additionally being attracted to the spacious, nicely renovated suburban houses.

Moreover, participants state that decreasing multiculturalism is problematic because it changes what they see as the nature of OudWest. Tristan and Ella explain why a multicultural and ethnically diverse neighbourhood is preferable. They indicate that they feel more at home in adjoining neighbourhood De Baarsjes, which is demographically comparable to Oud-West from 20 years ago. Tristan mainly talks about the cultural aspect, as he speaks fondly of Ramadan and its liveliness in the streets, and the neighbourly food sharing around that time. Ella describes the importance of diversity for a neighbourhood as something more political:

Because I think that diversity helps for a lot of... values. I think if you have a diverse area, people are used to that. And I think in the current society that would really help. (...) it's always easy for people to relate to groups if they know one person. So if they have like, a Moroccan neighbourhood where they get cookies from, or something with sugar, I think in general for people their whole view, 'oh that's so nice!', I think they will be more willing to welcome those people. 


\section{Transience of New Residents: A} Lack of Social Cohesion

In our interviews, all participants indicated that the changing housing market is closely linked with the transience of new residents in OudWest. With the new housing prices, people in more affluent positions are attracted to the area and buy into it. Key in understanding this new inhabitant, as mentioned by Chayka (2016), is that they are career-driven internationals who often do not settle in these houses permanently because they only remain in the city for a limited amount of time. Morits notes how the turnover in new residents is high: "they used to be here for longer than ten years, that's longer than two years or a couple of months, like what we have now". Michiel reports how he has experienced three different neighbours in the last 15 years. This high turnover rate shows how in the past years Oud-West has experienced an accelerated circulation of residential people. That way, the neighbourhood appears to be in an increasing state of transience, most noticed by local, nongentrifying residents. In connection to this, Willem describes a feeling of anonymity because he does not know his neighbours' names anymore. Alexandris also notes that "if you live somewhere you get a feeling for the place, but if you only live there for a couple of years... I can tell you, everyone knew each other a little bit around here. And nowadays, some people don't even know their neighbours, that has really changed".

Another new development is the use of residential properties for short-term sublets to tourists. Tourists rent an apartment through websites like Airbnb, and only stay for the weekend or a couple of days. This transient factor, previously non-existent in Oud-West, adds to local residents' growing distance to their neighbourhood and its people. Hendrik and Stephanie report on how four addresses in their street have become regularly rented out to Airbnb tourists. As an example, a two-floor apartment of a pand, previously occupied by two families, got sold to a single expat woman. She travels a lot for her job at an international bank, and rents out the apartment to Airbnb guests. Stephanie feels estranged by this change and expresses how this affects her relationship with the new owner: "I've only greeted her twice, and that was it. It's a huge change [...] From a man who was like the face of the neighbourhood to a woman who l've only spoken to twice in all these years." The presence of Airbnb is illustrated by Jessica and Fabian: "Every Friday afternoon it starts, and Sunday evening, Monday morning (...) you hear the little suitcases". Hence, what used to be a residential area is becoming increasingly popular among tourists and temporary residents, which is reflected in the high turnover rate.

This is problematic, as all but one of our interviewees indicate that a sense of neighbourhood community is an important part of living in Oud-West. Everyone has at least some family and friends in the area, and it is important to know your direct neighbours and see familiar faces in the wider area of surrounding streets. In the past five years, the area has become less social and more private. Hendrik explains that historically speaking, Oud -West used to have a close community and social appeal:

There are many people living here now that we don't have contact with at all (...) They're a little more reserved, or scared, I don't know. (...) There used to be a lot of social cohesion in this neighbourhood (...) there was a different kind of social environment, and the people were definitely more social. (...) there used to be a good mix of people.

\section{New People, New Mentalities: From Tolerance to Malleability}

Existing residents feel that new, transient inhabitants demand that the area around them change according to their own liking, disregarding the neighbourhood's existing community and their traditional local meeting places. According to Huub, the neighbourhood coordinator, new inhabitants are characterised by a different mentality and attitude towards the gentrified neighbourhood compared to those who have resided there before and 
during the gentrifying process. He notes that resident participation rates have risen in terms of initiatives and suggestions over the past five years, ranging from flowerpots to projects to support the local elderly. The typical new inhabitant of Oud-West does not hesitate to approach the municipality when they see room for improvement. Huub explains they are typically more highly educated, and understand how to navigate the bureaucratic system efficiently. They know who to contact within the municipality or local governance, and how to communicate their wishes clearly and effectively.

Existing residents claim that the other side of the assertiveness of the new, transient residents is that they lack the tolerance necessary to coexist in big cities. The new inhabitant has demands and wishes for the neighbourhood to change. Huub explains that "people consider the neighbourhood malleable, as long as they shout loud enough". This sense of malleability creates a certain clash between new inhabitants' wishes and those of local people and businesses. As an example he mentions a young family that moved in across from a bar, and then complained that "there is a bar on the corner, and it is so noisy, so it has to go" within a month of moving in. Most interviewees had similar stories of local business owners that struggle with new neighbours.

As explained previously, the closing of the local bakery as a result of complaints was highly controversial. All interviewees that spoke about the bakery indicated they find this mentality of new residents hard to understand, unacceptable, or even outrageous, "especially considering its important function as the last remaining bakery [De Rond in the neighbourhood]", as Hendrik notes. Willem mentions: "People [new residents] are maybe not used to living in a city. They come here, they buy a house and they start to complain (...) but it's a big city, you have to get used to it, you live with more people and not by yourself."

An interesting note is that all participants initially reflected positively on change. Yet when asked about specific incidents, such as the bakery closing down, strong emotional reactions were revealed. This shows that when confronted with events or changes in a concrete way, locals realise how elements of gentrification cause them to reconsider their initial positive evaluation. An illustration of this is Fatima, who had been very positive about change and respectful towards the new neighbours, until she was asked about the bakery:

We now don't have a bakery anymore (...) don't go live next to a bakery then. You know? The bakery was there first, and it's here to serve the area. What kind of person complains about that? It's incredible what kind of effect one address [person] can have. I think it's ridiculous. What are the rest of us supposed to do? (...) You should just go live somewhere else.

Huub is astonished by the amount of complaints by Oud-West's new residents, noting that: "I mean, you're moving to an area, so you firstly do research: what kind of people live here? What kind of shops? What kind of neighbourhood is it? So first you explore... And then you decide to buy the house, and the next moment you realise: I don't like this or that... and I'm going to make sure it disappears. That really happens, people literally do that."

\section{New Places for New People: Airspace and Changing Shop Fronts}

Interviewees evaluate the refurbished or newly opened cafés and shops with a feeling of displacement without being physically displaced. As an example, De Hallen and its concept stores, new hospitality and pricing were discussed and evoked mixed responses, but predominantly elicited a sense of exclusion. New places are appreciated, yet most participants do not seem entirely comfortable visiting them, feeling that they are directed at a different crowd. Willem describes his De Hallen visit as a certain form of appropriation of a culture and a lifestyle that is not his own, noting that "I don't really go there for food because I don't really feel like... It's like, maybe for urban young professionals and I don't feel that way. (...) It's also crowded and expensive (...) I think I was a hipster one day and first had frozen 
yoghurt and then a movie and, I felt happy with my girlfriend, which was nice (...) it's still expensive. I'd rather go to a pizza place where I go to for 28 years now or something." Participants that were less explicit about the exclusivity of the De Hallen still describe feelings of inaccessibility and socioeconomic divide. Stephanie's account reflects this:

Signing up for a [jewelry making] workshop was quite expensive, but you could also just walk through and have a look around. (...) I thought that was fun. (...) the building has really improved and looks nice. I think it's a shame that the completion... Well, I can't eat anything there because I simply cannot afford to. (...) It's really a huge contrast [to OudWest before]... I thought to myself: wow, this is really meant for the new people in the neighbourhood.

In sum, the only appeal for local interviewees is the convenience of having a cinema in De Hallen, which adds to their perception of the neighbourhood as comfortable. Almost all of the existing residents described their experiences with regards to the development of Airspace in Oud-West. Participants gave their own descriptions; for instance, Fabian stated that "[cafes] are all the same. First, they break the walls down and they leave part of the stones seen, and then the interior is like 'we use some different chairs, and some different tables (...) And a lot of rough wood and metal, and we put something hip on the outside'. But actually they all look the same but in a hip manner." The new Airspace interior design brings a rise in prices too, as Jessica notes: "Like, you would be able to get a beer for 2,50 maybe and now you go in a bar like that and a beer will be like 4 euros like without breaking a sweat. And not referring to a normal-size German beer here, we're referring to a small beer."

This homogenisation and sameness which participants reflect on illustrates an increasing socio-economic divide between people who can afford to frequent new places and those who cannot. The new Oud-Wester is in a more economically viable position compared to the previous residents, and is unequivocally part of the globalising cultural hegemony. Jessica gives a detailed characterisation of the new people who frequent Airspace and are progressively occupying space in Oud-West:

The people inside [those cafes] are also all exactly the same (...) They will all be wearing slightly too expensive jeans with some sort of white, too expensive white shirt or blouse, they all have exactly the same not super blonde-blonde hair with a bit of a spoeling [conditioner]. They all drive [ride] the same bikes, they all talk the same, they all have the same tan, and they probably all studied, like, communication and business.

The opening of new shops and hospitality businesses (see figure 1) often entails the closing or renovation of local shops and public places, which takes away key meeting points for local social interaction, such as the children's playground, which was replaced by a garage, or the bakery De Rond. Morits illustrates how he grew closer to his neighbours through visits to the local butcher. The queue was a great place to start a conversation with a familiar face. Over time, these casual interactions led to a form of friendship, which constitute very significant components of neighbourly sentiment. These are the local, affordable and smaller places where people meet and feel welcomed. In their absence, these important social interactions and opportunities to form relationships with neighbours are concurrently declining. Fatima shares her memory of the local snackbar [Dutch shop selling chips and other deep-fried snacks]. To her, it was the neighbourhood's cornerstone for socialising, where she used to meet her friends, describing it as gezellig [fun, social, cozy, welcoming].

Since its change of hands and renovations, the place changed significantly. The snackbar now sells organic chips, environmentally conscious snacks and locally produced soft drinks for a significantly higher price. Its brown walls and plastic interior have been replaced by a white, clean look with trendy furniture, fitting in with the earlier described concept of 'Airspace'. Fatima has not been there since the renovations: "it [used to be] more... open. It was easier to go there (...) when I walk past it now I 


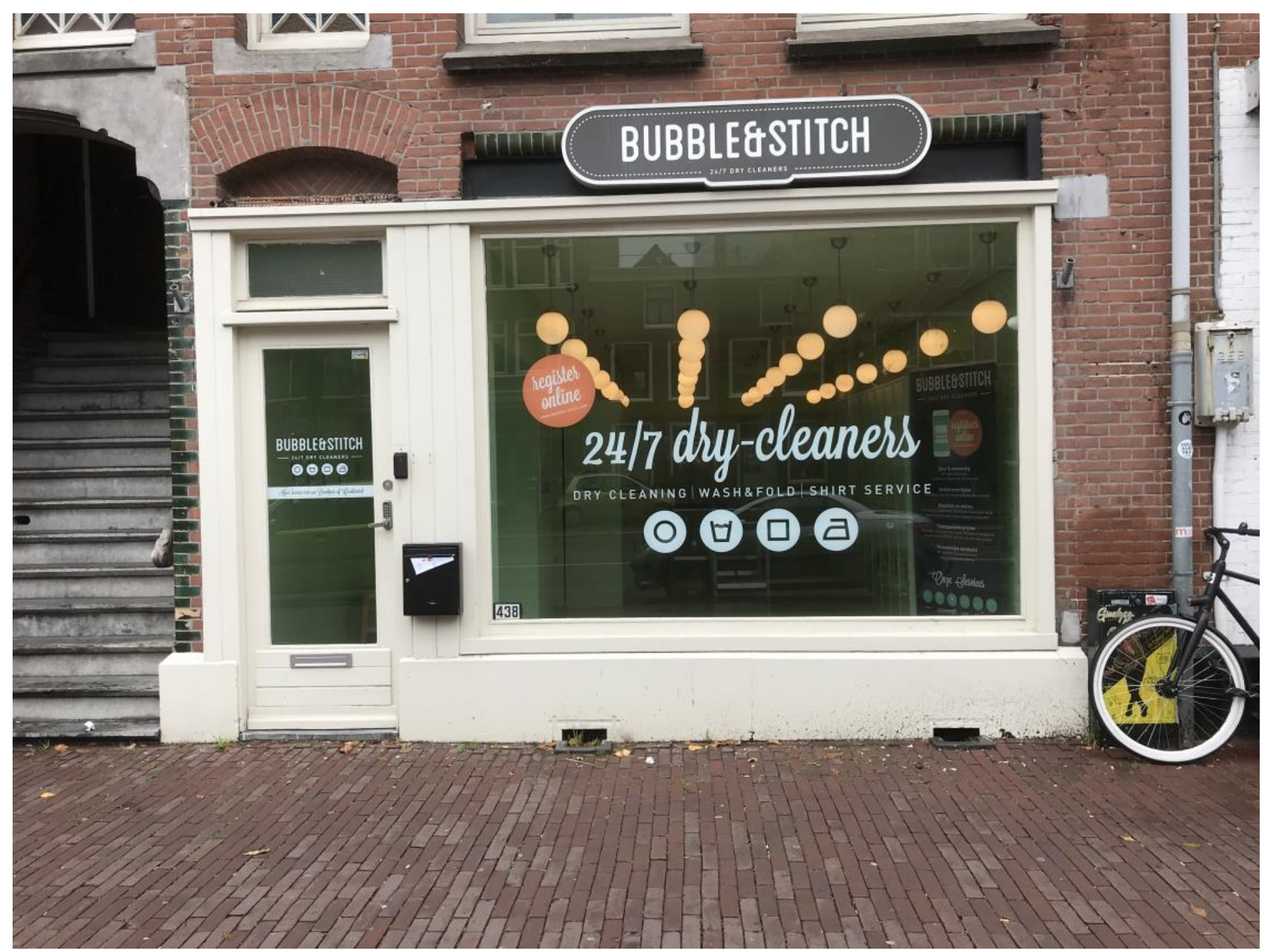

Figure 1: New service showing design markers of gentrification, photo taken by authors.

don't think to myself, "oh, I want to get some chips there", you know? (...) The organic-like stuff and the stuff that is really "in"... that kind of stuff is not my thing, really, I guess that's why I don't find the place appealing." Therefore, Airspace implies consequences for local residents' perceived identification with OudWest and the shops and hospitality it offers.

This influx of new people brings a different attitude and atmosphere to the neighbourhood. Tristan feels that the new cafes and bars have a different mentality towards customers, being less focused on the personal relationships. He also reflects on how 'old' restaurants and bar owners respond to the new customer's demand: "[they are] still the same people but they did see that they needed to pick up on things. Which gets a very weird result because (laughs) (...) now the stuff in there has Buddhas on them." This change alienates many locals as the familiar becomes more and more unfamiliar, which influences the sense of belonging and the attachment with the neighbourhood. Jessica gives a striking account of this, stating: "you go live abroad and then you come back to your place and you're like 'Oh, this is my place'. It's maybe not the best place in the world but it's my place. And now you walk there and it's like 'But... now it's their place'."

\section{Conclusion: The Changing Identity of Oud-West}

This research has provided rich insights into the lived experience of gentrification for locals in Amsterdam Oud-West. The accounts of research participants show how the neighbourhood has gone from an underinvested, lower socioeconomic and ethnically diverse area to a more popular and touristic one, with a transient, temporary population that earns a higher income. One of 
our most interesting findings is how this new group of transient inhabitants changes the neighbourhood. First, local shops and hospitality start to cater to this new type of global resident, adapting their style to become indistinguishable from coffee shops in other metropoles. This global phenomenon of 'Airspace' is powerfully present in Oud-West. These changes happen at the expense of local, authentic places that served as meeting places or were simply a vital part of the neighbourhood, such as the bakery. Locals report increasing disengagement with new residents, and a strong disassociation with new places, estranging locals from their neighbourhood, as if they are being displaced without actual physical removal. As a consequence, the increasing homogeneity in places and people comes at great (emotional) cost and spatial exclusion for locals.

This is especially manifested in the new residents' lack of tolerance and malleability, which demonstratively decreases locals' liveability in the neighbourhood. This final point has not been captured by previous literature thus far. The influx of tourists and Airbnb culture represent reasons for respondents to move to other neighbourhoods that resemble Oud-West before its gentrification. The changing housing market strongly affects the local populations' ability to live in Oud-West. All interviewees are continuously incentivised to leave, and with the demise of social housing, locals and young inhabitants can only remain in Oud-West if supported by their families financially or through inheritance. Besides the decreasing affordability of housing, new shops and hospitality represent socioeconomic exclusion to locals. Arguably, also the change in character makes these new places alienating. The decline of local shops triggered by gentrification results in a loss of social meeting points, and involvement in neighbourly socialising culture becomes increasingly difficult.

Participants were aware of the wider debate on the positive and negative impacts of gentrification. Because participants understood that gentrification is meant to improve the neighbourhood, many of them emphasised positive changes in general at the beginning of the interview. Yet, when confronted with concrete, specific examples different responses were triggered. The closing of De Hallen and the De Rond bakery evoked emotional reactions and clearly demonstrate that a more thorough evaluation brings out more negative aspects of gentrification. 


\section{Appendix I: Overview of participants}

\begin{tabular}{|c|c|c|c|c|}
\hline Type of Interview & Name & Age & Ethnicity & Form of Residency \\
\hline Individual & Carolina & 20 & Dutch & $\begin{array}{l}\text { Parents own } \\
\text { property }\end{array}$ \\
\hline Individual & Ella & 32 & $\begin{array}{l}\text { Dutch/North } \\
\text { African }\end{array}$ & Property owner \\
\hline Individual & Felix & 64 & Dutch & Tenant \\
\hline Individual & Geert & 65 & Dutch & Property owner \\
\hline Individual & Mortis & 58 & Dutch & Property owner \\
\hline Individual & Michiel & 51 & Dutch & Property owner \\
\hline Individual & Tristen & 27 & Dutch & Tenant \\
\hline Individual & Willem & 28 & Dutch & Tenant \\
\hline $\begin{array}{l}\text { Mother and } \\
\text { daughter }\end{array}$ & Jaida and Fatima & 51 and 27 & North African & Tenant \\
\hline $\begin{array}{l}\text { Father and } \\
\text { daughter }\end{array}$ & Fabian and Jessica & 49 and 26 & Dutch & Tenant \\
\hline $\begin{array}{l}\text { Father and } \\
\text { daughter }\end{array}$ & $\begin{array}{l}\text { Hendrick and } \\
\text { Stephanie }\end{array}$ & 58 and 24 & Dutch & Property owner \\
\hline $\begin{array}{l}\text { Father and son/ } \\
\text { Local business }\end{array}$ & $\begin{array}{l}\text { Demitri and } \\
\text { Alexandris }\end{array}$ & 62 and 29 & Southern European & - \\
\hline $\begin{array}{l}\text { Neighbourhood } \\
\text { Coordinator }\end{array}$ & Huub & - & Dutch & - \\
\hline
\end{tabular}




\section{References}

Agora Europa (2015). De Hallen Amsterdam nieuwe hotspot in Nieuw West. Retrieved on November 2017 from http://www.agoraeuropa.nl/967-Tramremise-de-Hallen.html

Atkinson, R. (2004). The evidence on the impact of gentrification: new lessons for the urban renaissance?. European Journal of Housing Policy 4 (1): 107-131.

AT5 (2016). Laatste dag nachtbakker Overtoom ingegaan. Retrieved from: http://www.at5.nl/artikelen/164070/laatste-dagnachtbakker-overtoom-ingegaan

Borrel, D. (September 16, 2017). Van Oud-West naar Goud-West. NRC. Retrieved on May 15, 2017 from https://www.nrc.nl/ nieuws/2017/09/16/van-oud-west-naar-goud-west- 12943096a1573456

Boterman, W. R., \& Gent, W. P. (2014). Housing liberalisation and gentrification: The social effects of tenure conversions in Amsterdam. Tijdschrift voor economische en sociale geografie 105 (2): 140-160.

Butler, T. (2003). Living in the bubble: gentrification and its 'others' in North London. Urban studies 40 (12): 2469-2486.

City of Amsterdam (2016). Property value - sale price in m2. Accessed January 19, 2017. http://maps.amsterdam.nl/woningwaarde/

Chayka, K. (2016). Welcome to Airspace. The Verge. Accessed January 15, 2017. http://www.theverge.com/2016/8/3/12325104/airbnbaesthetic-global-minimalism- startup-gentrification

Chayka, K. (2016). Same old, same old. How the hipster aesthetic is taking over the world. The Guardian. Accessed January 15, 2017. https://www.theguardian.com/commentisfree/2016/aug/06/ hipster-aesthetic-taking-over-world

Doucet, B. (2009). Living through gentrification: subjective experiences of local, non- gentrifying residents in Leith, Edinburgh. Journal of Housing and the Built Environment 24 (3): 299-315.

Doucet, B., van Kempen, R., \& van Weesep, J. (2011). 'We're a rich city with poor people': municipal strategies of new-build gentrification in Rotterdam and Glasgow. Environment and Planning A 43 (6): 1438-1454.

Gemeente Amsterdam (2014). Amsterdam groeit door. Onderzoek, 
Informatie en Statistiek. Retrieved from: https://

www.ois.amsterdam.nl/nieuwsarchief/2014/ amsterdam-groeitdoor

Gemeente Amsterdam (2017a). Gebiedsanalyse 2017 5. Oud-West / De Baarsjes Stadsdeel West. Onderzoek, Informatie en Statistiek. Retrieved from: https://

www.ois.amsterdam.nl/.../1654/2017_gebiedsanalyse_5.pdf

Gemeente Amsterdam (2017b). Stadsdelen in cijfers 2017.

Onderzoek, Informatie en Statistiek. Retrieved from: https:// www.ois.amsterdam.nl/pdf/ 2017_stadsdelen_in_cijfers.pdf

Gent, W. V. (2013). Neoliberalisation, housing institutions and variegated gentrification: How the 'Third Wave' broke in Amsterdam. International Journal of Urban and Regional Research 37 (2): 503-522.

Het Amsterdamse Bureau voor Onderzoek en Statistiek (2002). Stadsdelen en Buurtcombinaties in cijfers 2002. Retrieved from: https://www.ois.amsterdam.nl/ pdf/2002_stadsdelen_in_cijfers.pdf

Lees, L. (2008). Gentrification and social mixing: towards an inclusive urban renaissance?. Urban Studies 45 (12): 2449-2470.

Posthumus, S. (December 28, 2016). Fotoboek ter ere van sluiting nachtbakker Overtoom. Het Parool. Retrieved on January 12, 2017 from https://www.parool.nl/stadsgids/fotoboek-ter-ere-vansluiting-nachtbakker- overtoom a4440786/

Schade, C. (1981). Woningbouw voor arbeiders in het 19de-eeuwse Amsterdam. Amsterdam: Van Gennep.

Shaw, K. S., \& Hagemans, I. W. (2015). 'Gentrification Without Displacement' and the Consequent Loss of Place: The Effects of Class Transition on Low-Income Residents of Secure Housing in Gentrifying Areas. International Journal of Urban and Regional Research 39 (2): 323-341.

Slater, T. (2006). The eviction of critical perspectives from gentrification research. International Journal of Urban and Regional Research 30 (4): 737-757.

Sloane, M. (2016). Inequality by design? Why we need to start talking about aesthetics, design and politics. London School of Economics. Accessed January 16, 2017. http://blogs.Ise.ac.uk/ researchingsociology/2016/09/12/inequality-by-design-why-weneed-to-start-talking-about-aesthetics-design-and-politics/

Van Criekingen, M. (2009). Moving in/out of Brussels' historical core in the early 2000s: migration and the effects of gentrification. Urban Studies 46 (4): 825-848.

This work is licensed under a Creative Commons Attribution-NonCommercialNoDerivatives 4.0 International License. 